\title{
X. Wu, N.F. Miller, P. Crabtree. « Agro-Pastoral Strategies and Food Production on the Achaemenid Frontier in Central Asia: A Case Study of Kyzyltepa in Southern Uzbekistan »
}

Johanna Lhuillier

\section{(2) OpenEdition \\ Journals}

Édition électronique

URL : http://journals.openedition.org/abstractairanica/44729

DOI : 10.4000/abstractairanica.44729

ISBN : 1961-960X

ISSN : 1961-960X

Éditeur :

CNRS (UMR 7528 Mondes iraniens et indiens), Éditions de l'IFRI

\section{Référence électronique}

Johanna Lhuillier, «X. Wu, N.F. Miller, P. Crabtree. «Agro-Pastoral Strategies and Food Production on the Achaemenid Frontier in Central Asia: A Case Study of Kyzyltepa in Southern Uzbekistan » », Abstracta Iranica [En ligne], Volume 37-38-39 | 2018, document 9, mis en ligne le 30 décembre 2018, consulté le 26 septembre 2020. URL : http://journals.openedition.org/abstractairanica/44729 ; DOI : https://doi.org/10.4000/abstractairanica.44729

Ce document a été généré automatiquement le 26 septembre 2020.

Tous droits réservés 
X. Wu, N.F. Miller, P. Crabtree. « Agro-Pastoral Strategies and Food Production on the Achaemenid Frontier in Central Asia: A Case Study of Kyzyltepa in Southern Uzbekistan »

Johanna Lhuillier

\section{RÉFÉRENCE}

X. Wu, N.F. Miller, P. Crabtree. « Agro-Pastoral Strategies and Food Production on the Achaemenid Frontier in Central Asia: A Case Study of Kyzyltepa in Southern Uzbekistan », Iran LIII, 2015, 93-117.

1 Cet article livre une première étude des restes archéobotaniques (analysés par Naomi F. Miller) et archéozoologiques (par Pam Crabtree) de l'un des rares sites que l'on peut attribuer à la période achéménide en Asie centrale, Kyzyl-tepe en Bactriane ouzbèke (mission dirigée par Wu Xin et Leonid Sverchkov). Les échantillons considérés dans l'étude proviennent à la fois de contextes "achéménides " et du début de la période hellénistique, datation basée sur la stratigraphie et sur l'étude typo-chronologique des assemblages céramiques, les auteurs faisant le choix de ne pas prendre en compte les datations radiocarbones des échantillons, qui livrent une datation discordante, plus ancienne de quelques siècles. Quoi qu'il en soit, ce type d'étude croisée demeure rare pour l'âge du Fer et la période hellénistique en Asie centrale et les premières données que livre cet article seront fort utiles. 
2 La présence de blé, d'orge et surtout de millet parmi les restes archéobotaniques permet aux auteurs de conclure à une agriculture irriguée en été afin d'augmenter la production. En ce qui concerne les restes archéozoologiques, les auteurs identifient une majorité d'espèces domestiques, qui auraient d'après les profils d'abattage été prioritairement destinées à la production de viande et de lait, bien que d'autres usages ne soient pas exclus. La présence d'espèces sauvages indique une exploitation des espaces environnants, steppes, déserts et vallées. Une salutaire tentative de mise en perspective avec les données archéoozoologiques de sites centrasiatiques contemporains ne prend malheureusement en compte que les rares publications anglophones. La partie dévolue aux analyses se conclut par une mise en parallèle avec les rares sources textuelles disponibles, notamment les documents araméens de Bactriane ancienne et les tablettes des Fortifications de Persépolis. Au terme de cette analyse croisée, les auteurs reconstituent une économie reposant à la fois sur le pastoralisme et une agriculture en train de s'intensifier, ce qu'ils interprètent comme la conséquence de la domination achéménide de l'Asie centrale.

\section{AUTEURS}

\section{JOHANNA LHUILLIER}

UMR 5133 CNRS-Université de Lyon 